\title{
Pemanfaatan Gas Buang Motor Diesel Untuk Pengering Tepung Tapioka Menggunakan Shell and Tube Exchanger
}

\author{
Tarto Raharjo ${ }^{1}$ \\ ${ }^{1}$ Politeknik Muhammadiyah Pekalongan, Kajen, Pekalongan, Jawa Tengah 51161, Indonesia \\ email : tartoraharjo@gmail.com
}

\begin{abstract}
ABSTRAK
Teknik pengeringan memegang peran yang sangat penting untuk menentukan kualitas dan kontinuitas dalam proses pembuatan tepung tapioka. Secara tradisional proses pengeringan dilakukan oleh para petani dengan memanfatkan panas matahari, namun kendala terjadi ketika musim penghujan datang sedangkan produksi harus tetap berjalan untuk memenuhi kebutuhan.Secara umum yang terjadi saat ini kendala produksi tapioka adalah pada proses pengeringannya, dimana saat ini hanya dilakukan dengan cara tradisional yang sangat membutuhkan lahan yang luas dan sangat bergantung pada cuaca dengan panas matahari yang banyak. Penelitian ini bertujuan melakukan analisis desain sistem pengering buatan, khusus membahas alat penukar kalor yang memanfaatkan energi panas gas buang diesel stasioner dengan udara sebagai fluida pemindah panas.Penelitian ini dilakukan dengan menvariasikan variabel-variabel bebas yang telah ditentukan, dan pembahasan akan fokus pada analisis perpindahan panas (heat transfer). Dengan memperhitungkan parameter dari dimensi utama alat penukar kalor, yaitu luas penampang (A), panjang pipa (L), diameter luar pipa (do) dan Jumlah pipa (Nt). Hasil penelitian ini adalah pada kondisi optimum desain dimensi alat penukar kalor dari pengering tapioka shell dan tube dengan metode eksperimen full factorial, terdapat desain dimensi pengering tapioka yang paling optimum, yaitu kondisi desain no 53 dengan jumlah tube 13,02 dan panjang tube $5 \mathrm{~m}$, serta koefisien perpindahan panas global U sebesar 240,51 W/m2.K kondisi desain ini dipilih adalah adanya faktor jumlah tube yang sedikit, dan mempunyai nilai perpindahan panas global U yang besar dan berdasarkan jumlah tube dan panjang tube dari kondisi desain tersebut maka kondisi desain yang paling optimum dengan jumlah tube 13,02 yaitu dengan diameter tube $0.0508 \mathrm{~m}$, panjang tube $5 \mathrm{~m}$, susunan antar tube CL, 45o, jarak antar tube PR 1.5 dan Number of Transfer Unit NTU sebesar 0,24 .
\end{abstract}

Kata kunci : alat penukar kalor, full factorial, number of transfer unit, pengering buatan, shell dan tube, teknik pengeringan.

\begin{abstract}
Drying techniques play a very important role to determine the quality and continuity in the process of making tapioca flour. Traditionally the drying process is carried out by farmers by utilizing solar heat, but obstacles occur when the rainy season comes while production must continue to meet needs. In general what is happening now is the constraint of tapioca production is in the drying process, which is currently only carried out in a traditional way that requires a large area and is very dependent on the weather with a lot of solar heat. This study aims to analyze the design of artificial dryer systems, specifically discussing heat exchangers that utilize stationary diesel exhaust gas heat energy with air as a heat transfer fluid. This research is conducted by varying the independent variables that have been determined, and the discussion will focus on the analysis of heat transfer. By taking into account the parameters of the main dimensions of the heat exchanger, namely cross-sectional area (A), pipe length (L), pipe outer diameter (do) and pipe number (Nt). The results of this study are at the optimum condition of the dimensions of the heat exchanger design of tapioca shell and tube dryers with a full factorial experimental method, there is the optimum design of tapioca dryer dimensions, namely design condition 53 with the number of tubes 13.02 and tube length $5 \mathrm{~m}$ and the global $U$ heat transfer coefficient of $240.51 \mathrm{~W} / \mathrm{m} 2 . \mathrm{K}$. This design condition is chosen is the presence of a small number of tube factors, and has a large global $U$ heat transfer value and based on the number of tubes and tube lengths of the design conditions, the design conditions the most optimum with the number of tubes 13.02 with tube diameter of $0.0508 \mathrm{~m}$, length of tube $5 \mathrm{~m}$, arrangement between CL tubes, 45o, distance between tube PR 1.5 and Number of Transfer Unit NTU of 0.24 .
\end{abstract}

Kata kunci : artificial dryers, drying techniques, full factorial, heat exchangers, number of transfer units, shell and tube 


\section{PENDAHULUAN}

Keanekaragaman bahan pangan sangat penting untuk mengatasi masalah ketergantungan pada satu bahan pangan pokok saja[1]. Salah satu caranya adalah dengan mengolah ketela pohon menjadi berbagai macam jenis makanan,selain mempunyai rasa khas juga dapat tahan lama disimpan[2].Ketela pohon merupakan salah satu bahan makanan sumber karbohidrat. Hal ini sesuai dengan program pemerintah, khususnya dalam mengatasi masalah kebutuhan bahan pangan, terutama bahan pangan non beras[3]. Ketela pohon dalam keadaan segar tidak tahan lama. Untuk pemasaran yang memerlukan waktu lama, ketela pohon harus diolah dulu menjadi bentuk lain yang lebih awet, seperti gaplek, tapioka (tepung ketela pohon), tape, peuyeum, dll[4].

Teknik pengeringan memegang peran yang sangat penting untuk menentukan kualitas dan kontinuitas dalam proses pembuatan tepung tapioka. Secara tradisional proses pengeringan dilakukan oleh para petani dengan memanfatkan panas matahari, namun kendala terjadi ketika musim penghujan datang sedangkan produksi harus tetap berjalan untuk memenuhi kebutuhan[5].

Penelitian ini bertujuan untuk melakukan analisis desain sistem pengering buatan, khusus membahas alat penukar kalor yang memanfaatkan energi panas gas buang diesel stasioner dengan udara sebagai fluida pemindah panas. Secara umum yang terjadi saat ini kendala produksi tapioka adalah pada proses pengeringannya, dimana saat ini hanya dilakukan dengan cara tradisional yaitu dengan menjemur secara langsung. Pengeringan tradisional ini memiliki kelemahan dalam hal teknik dan ekonomis[6].

Penelitian ini dilakukan dengan menvariasikan variabel-variabel bebas seperti yang telah disebutkan diatas, dan pembahasan akan fokus pada analisis perpindahan panas (heat transfer). Dengan memperhitungkan parameter dari dimensi utama alat penukar kalor, yaitu luas penampang (A), panjang pipa (L), diameter luar pipa (do) dan Jumlah pipa (Nt)[7].

\section{METODE PENELITIAN}

Penelitian ini dilakukan dengan menggunakan metode atau pendekatan secara teoritis dan eksperimental. Penelitian ini dilakukan di pabrik pengolah tepung tapioka "H.Toyib" di daerah Comal, Pemalang, Jawa Tengah. Waktu pelaksanaan penelitian ini selama kurang lebih 5 bulan dalam bulan Juli sampai dengan bulan Desember 2011.

Dalam penelitian ini digunakan metode studi literatur dengan mengumpulkan data-data serta mempelajari artikel-artikel dan buku-buku referensi yang berkaitan dengan sistem pengeringan tepung tapioka dan gas buang mesin diesel.Dari data yang terkumpul kemudian dibuat suatu rancangan sistem alat pemindah kalor dengan kapasitas sesuai kebutuhan dengan mengacu pada dasar-dasar teori yang ada dan dari penelitian-penelitian sebelumnya.

Dari rancangan berdasarkan perhitungan kemudian dilakukan optimasi desain alat penukar kalor. Menggunakan perhitungan full factorial dan terakhir hasil optimasi dengan program HTRI, sehingga diketahui kinerja alat penukar kalor tersebut apabila nanti dioperasikan.

Gambar dibawah ini merupakan gambar dari diagram alir penelitian.

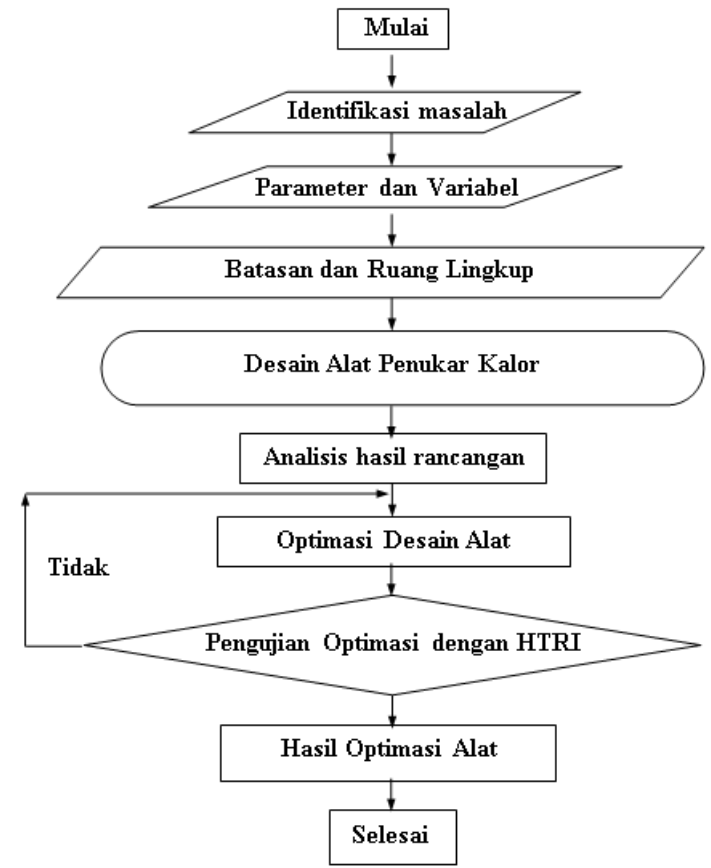

Gambar 1. Diagram Alir Penelitian

\section{HASIL DAN PEMBAHASAN}

Berdasarkan data dari perhitungan dimensi utama pada alat penukar kalor (Pengering) pada mesin pendingin, selanjutnya adalah melakukan perhitungan optimasi desain dari alat penukar kalor dengan menggunakan pengujian desain secara full factorial sehingga memperoleh hasil yang optimum dari alat tersebut dan juga memperhatikan batasan dan ruang lingkup dari penelitian.

Dengan menggunakan persamaan dan tabel.1 dibawah, eksperimen full factorial, memilih salah satu desain yaitu: 
Tabel 1.Variabel bebas dan level eksperimen.

\begin{tabular}{|c|l|c|c|c|}
\hline Kode & \multicolumn{1}{|c|}{ Variabel Bebas } & Level 1 & Level 2 & Level 3 \\
\hline A & Diameter Tube, (d, m) & 0.0254 & 0.0381 & 0.0508 \\
\hline B & Susunan Tubel Lay out, (CL , $)$ & 30 & 45 & 60 \\
\hline C & Jarak antar Tube Pitch Ratio, (PR) & 1,25 & 1,35 & 1,50 \\
\hline D & Panjang Sbell (L) & 4 & 5 & 6 \\
\hline
\end{tabular}

Pada penelitian ini sebagai variable bebas dan ruang lingkup desain dipilih sebagai berikut:

1. Diameter pipa dipilih berukuran : $25.4 \mathrm{~mm}$; $38.1 \mathrm{~mm} ; 50.8 \mathrm{~mm}$

2. Bentuk susunan pipa dipilih berbentuk: 30 o; 45 o; 60 o

3. Jarak antar tube dipilih: $1.25 ; 1.35 ; 1.50$

4. Panjang shell dipilih ukuran : 4, 5, 6

Berdasarkan tabel eksperimen full factorial diatas bahwa perhitungan desain optimal dilakukan pada kondisi desain sebagai berikut:

1. Diameter pipa adalah : $50.8 \mathrm{~mm}$

2. Bentuk susunan pipa adalah: 450 dengan CL 1

3. Jarak antar pipa adalah PR 1.50

4. Panjang tube adalah : $5 \mathrm{~m}$

Demikian selanjutnya untuk kondisi desain lainnya sampai dengan kondisi no 81 hasil dari perhitungan eksperimen full factorial dilakukan dan diperoleh pengaruh rata-rata dari masing-masing faktor terhadap jumlah tube dan diameter shell sehingga diperoleh hasil kondisi desain yang optimum. Pengaruh rata-rata faktor diameter tube $\mathrm{D}_{\mathrm{o}}$ terhadap jumlah tube yang ada pada kondisi desain dijelaskan oleh grafikpada gambar.2 sebagai berikut :

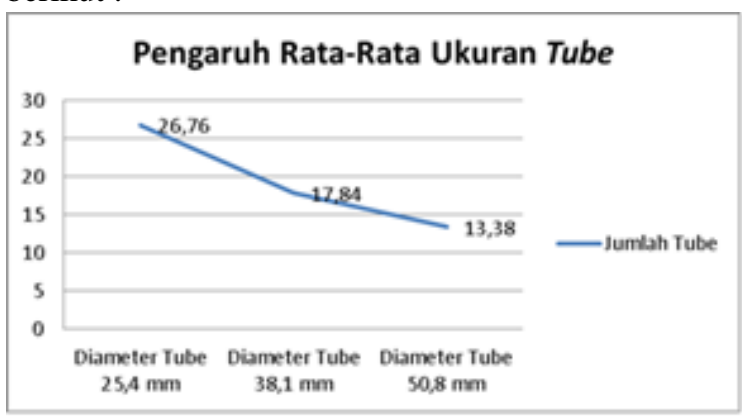

Gambar 2. Grafik pengaruh rata-rata ukuran tube.

Pengaruh rata-rata faktor tube layout/CL terhadap jumlah tube yang ada dijelaskan oleh grafik pada gambar.3 sebagai berikut :

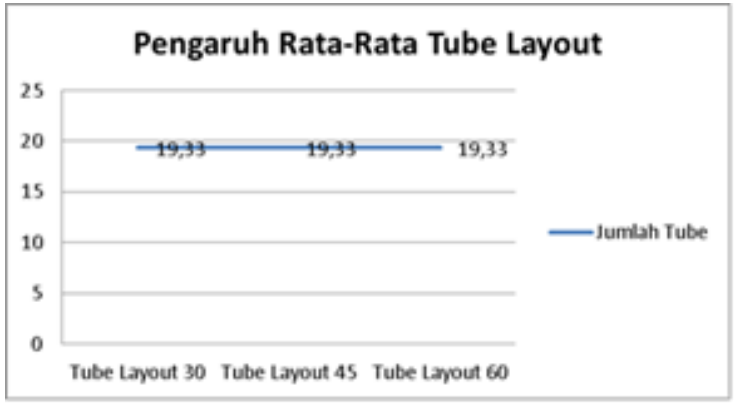

Gambar 3. Grafik pengaruh rata-rata tube layout.

Dari grafik diatas menunjukkan bahwa faktor susunan antar tube layout (CL), memiliki nilai yang sama sehingga didalam desain alat penukar kalor ini layout tidak memberikan pengaruh yang berarti terhadap jumlah tube yang didesain.Pengaruh ratarata faktor pitch ratio PR terhadap jumlah tube dijelaskan oleh grafik pada gambar.4 sebagai berikut

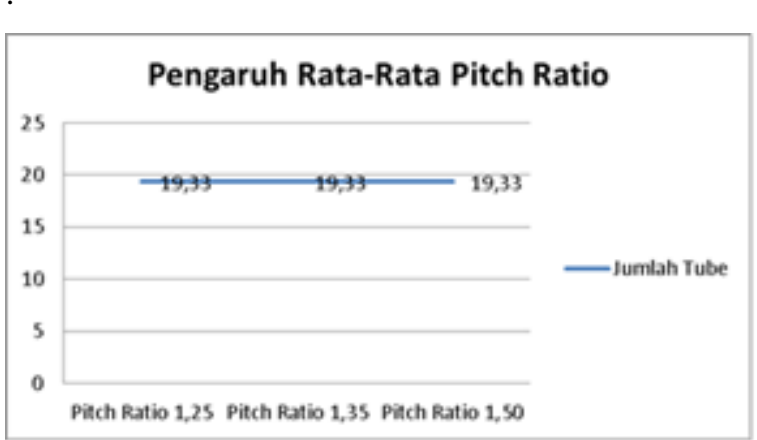

Gambar 4. Grafik pengaruh rata-rata pitch ratio

Dari grafik diatas memperlihatkan bahwa faktor Pitch Ratio (PR), memiliki nilai yang sama sehingga didalam desain alat penukar kalor ini Pitch Ratio tidak memiliki pengaruh yang berarti kepada jumlah tube di alat penukar kalor yang didesain.Pengaruh rata-rata faktor Panjang tube L terhadap jumlah tube terhadap yang ada dijelaskan oleh grafik pada gambar.5 sebagai berikut :

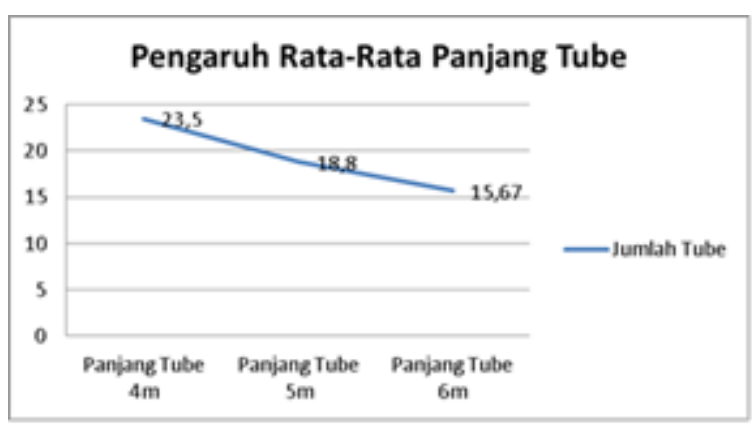

Gambar 5. Grafik pengaruh rata-rata panjang tube.

Dari grafik diatas menunjukkan bahwa Panjang tube $5 \mathrm{~m}$ memberikan pengaruh yang lebih baik dari pada kedua Panjang tube yang lainnya.Pengaruh rata-rata faktor diameter tube Do terhadap diameter shell yang ada pada kondisi desain ditunjukkan oleh grafik pada gambar.6 sebagai berikut : 


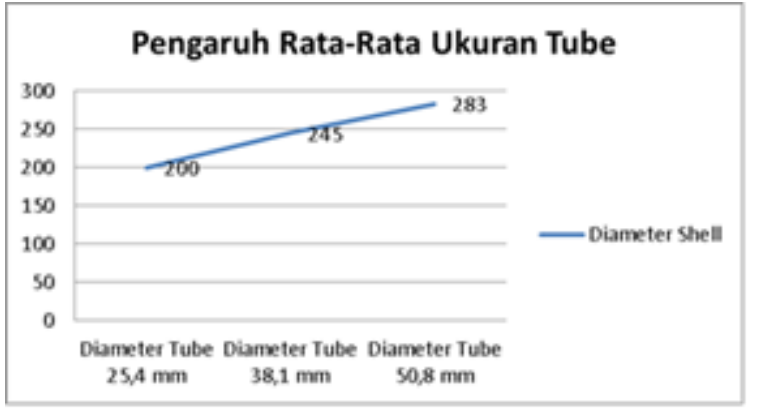

Gambar 6. Grafik pengaruh rata-rata ukuran tube.

Dari grafik diatas dapat diamati bahwa ukuran tube diameter $50.8 \mathrm{~mm}$, memberikan pengaruh yang lebih baik dari pada dua ukuran tube lainnya di mana diameter shell yang yaitu $283 \mathrm{~mm}$.Pengaruh ratarata faktor tube layout CL terhadap diameter shell yang ada ditunjukkan oleh grafik pada gambar.7. Dari grafiktersebut dapat diamati bahwa susunan antar tube (lay out) 45o, memberikan pengaruh yang lebih baik dari pada susunan antar tube (lay out) lainnya.

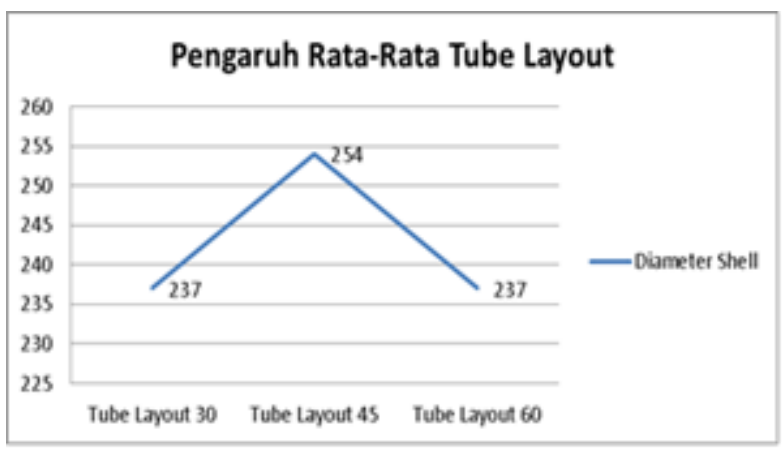

Gambar 7. Grafik pengaruh rata-rata faktor tube layout.

Pengaruh rata-rata faktor pitch ratio PR terhadap diameter shell terhadap yang ada ditunjukkan oleh grafik pada gambar.8 sebagai berikut :

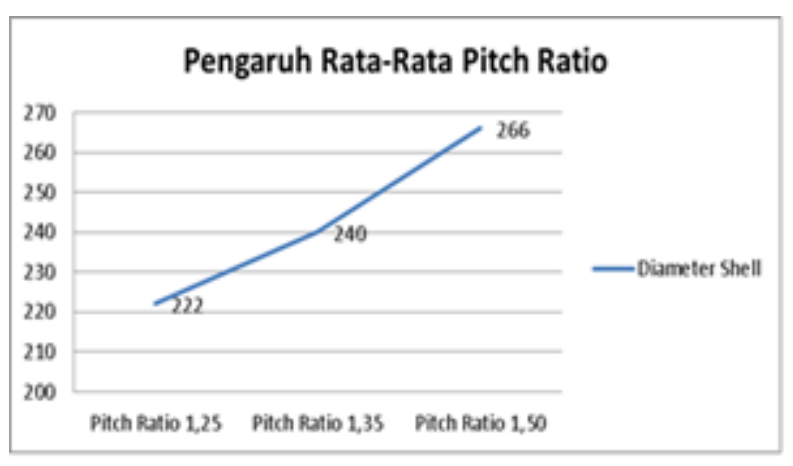

Gambar 8. Grafik pengaruh rata-rata faktorpitch ratio.

Dari grafik diatas dapat diamati bahwa jarak antar tube (Pitch rasio) 1.35 memberikan pengaruh yang lebih baik dari pada dua jarak antar tube (Pitch ratio) lainnya di mana memberikan hasil desain yaitu 240 $\mathrm{mm}$.

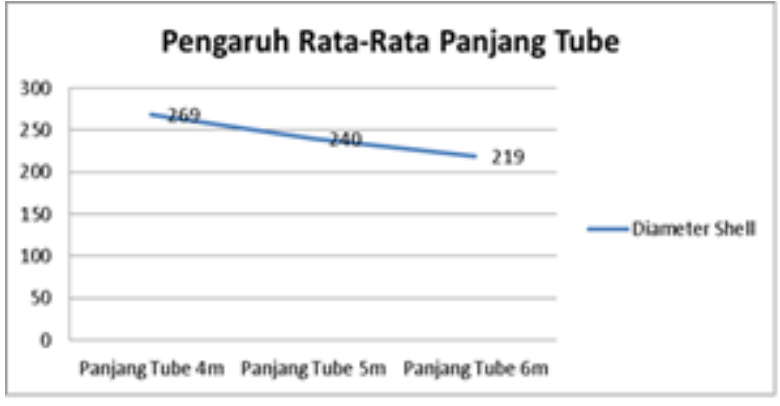

Gambar 9. Grafik pengaruh rata-rata faktorpanjang tube.

Dari grafik tersebut diatas dapat diamati bahwa Panjang tube $5 \mathrm{~m}$ memberikan pengaruh yang lebih baik dari pada kedua Panjang tube yang lainnya dimana memberikan hasil desain dengan dimensi yang paling ekonomis.

Perhitungan respons rata-rata diatas digunakan untuk mengetahui pengaruh tiap tiap level faktor terhadap hasil perhitungan. Hasil perhitungan respons rata-rata digunakan untuk mengidentifikasi level faktor yang dominan terhadap hasil perhitungan desain. Tabel 2 berikut ini menyajikan hasil perhitungan atau respon rata-rata faktor level terhadap jumlah tube dan diameter shell.

Tabel 2. Pengaruh rata-rata faktor terhadap masingmasing level.

\begin{tabular}{|c|c|c|c|c|}
\hline No & Uraian & Notexi & $\mathrm{N}_{1}$ (tabe) & $D_{v}(\mathrm{~mm})$ \\
\hline 1 & Pengaruh ata -rata Diameter tube $25.4 \mathrm{~mm}$ & A1 & 26.76 & 200 \\
\hline 2 & Pengaruh rata-rata Diameter tube $38.1 \mathrm{~mm}$ & A2 & 1784 & 245 \\
\hline 3 & Pengaruh rats-rats Diameter tube $50.8 \mathrm{~mm}$ & A3 & 13.38 & 283 \\
\hline 4 & Pengaruh rata-rata Lay Ost 30 derajut & B1 & 1933 & 237 \\
\hline 5 & Pengaruh tata-tata Lay Ose 45 detrijat & B2 & 1933 & 254 \\
\hline 6 & Pengaruh tata-tats Lay Ose 60 derajut & B3 & 1933 & 237 \\
\hline 7 & Pengaruh rata -rata Pisch Ranio 1.25 & c1 & 1933 & 222 \\
\hline 8 & Pengaruh rata-rata Pitch Ratio 135 & c2 & 1933 & 240 \\
\hline 9 & Pengaruh rata-rata Piseh Ratio 150 & c3 & 1933 & 266 \\
\hline 10 & Pengaruh rata-rata Pavjaug tabe 4 = & D1 & 23.5 & 269 \\
\hline 11 & Pengaruh rata-rata Payjang tabe $5 \mathrm{~m}$ & D2 & 188 & 240 \\
\hline 12 & Pengaruh rata-rata Pavjang tobe $6 \mathrm{~m}$ & D3 & 15.67 & 219 \\
\hline
\end{tabular}

Selanjutnya hasil dari perhitungan eksperimen full factorial dilakukan dan diperoleh pengaruh rata-rata dari masing-masing faktor terhadap jumlah tube dan diameter shell sehingga diperoleh hasil kondisi desain yang optimum. Kondisi optimum alat penukar kalor dapat dilihat seperti pada Tabel.3 berikut ini: 
Tabel 3. Dimensi desain optimum hasil eksperimen full factorial.

\begin{tabular}{|c|c|c|c|c|}
\hline No & Parameter/Dimensi & Simbol & Nilai & Sataan \\
\hline 1 & Diameter Shell & Ds & 377 & $\mathrm{~mm}$ \\
\hline 2 & Panjang & $L$ & 5 & m \\
\hline 3 & Jumlah Tube & $N \xi$ & 13 & Buah \\
\hline 4 & Diameter tube & $d_{0}$ & 50.8 & $\mathrm{~mm}$ \\
\hline 5 & Koef Perpindahan Panas Menyelaruh & $v$ & 240.51 & $\mathrm{~W} / \mathrm{m}^{2} \mathrm{~K}$ \\
\hline 6 & Beban Termal & $Q$ & 360366.9 & w \\
\hline 7 & Temperatur gas masuk & $\pi$ & 300 & $\boldsymbol{C}$ \\
\hline 8 & Temperatur gas keluar & $T h$ & 267 & ${ }^{\star C}$ \\
\hline 9 & Temperatur vdara Masuk & $T_{e i}$ & 29 & ${ }^{\circ} \mathrm{C}$ \\
\hline 10 & Temperatur udara Kelasar & $T_{t \omega}$ & 65 & ${ }^{\circ} \mathrm{C}$ \\
\hline 12 & Laju Aliran Massa gas & $m$ & 10.43 & $\mathrm{~kg} / \mathrm{s}$ \\
\hline 13 & Laju Aliran Massa udara & $m_{t}$ & 13.46 & $\mathrm{~kg} / \mathrm{s}$ \\
\hline 14 & Pinch Rasio & $P R$ & 1.50 & \\
\hline 15 & Susunan antar trube & $C L$ & 45 & Derajat \\
\hline 16 & Jumlah one pass & $C T P$ & 0.93 & \\
\hline
\end{tabular}

Dari tabel.3 diatas memperlihatkan pengujian dari desain awal full factorial, data spesifikasi alat penukar kalor dengan hasil program HTRI menunjukkan kesamaan data dimensi utama untuk mendesain alat penukar kalor tipe shell dan tube pada kondensor di mesin pendingin. Sehingga dapat dibuat perbandingan antara desain awal dari dimensi utama alat penukar kalor tipe shell dan tube dibandingkan dengan analisis dimensi dengan program HTRI dapat dilihat pada tabel.4 seperti berikut ini:

Tabel 4. Data perbandingan hasil perhitungan full factorial dengan validasi perangkat lunak HTRI.

\begin{tabular}{|c|c|c|c|c|c|}
\hline \multirow[b]{2}{*}{ No } & \multirow[b]{2}{*}{ Parameter / Dimensi } & \multirow[b]{2}{*}{ Simbol } & \multicolumn{2}{|c|}{ Nilai } & \multirow[b]{2}{*}{ Satwan } \\
\hline & & & $\begin{array}{c}\text { Full } \\
\text { factori } \\
\text { al }\end{array}$ & HTRI & \\
\hline 1 & Diameter Shell & Dr & 377 & 377 & $\mathrm{~mm}$ \\
\hline 2 & Panjang & $L$ & 5 & 5 & $\mathrm{~m}$ \\
\hline 3 & Jumlah Tube & $N_{\mathrm{s}}$ & 13 & 13 & Buah \\
\hline 4 & Diameter tube & $d$ & 50.8 & 50.8 & $\mathrm{~mm}$ \\
\hline 5 & Koef: Perpindahan Panas Meayeluruh & $U$ & 240.51 & 243.88 & $\mathrm{~W} / \mathrm{m}^{2} \mathrm{~K}$ \\
\hline 6 & Beban Termal & $Q$ & 360366.9 & 3603669 & $w$ \\
\hline 7 & Temperanur gas mavik & $\pi$ & 300 & 300 & c \\
\hline 8 & Temperatur gas keluar & $\pi$ & 267 & 267 & ${ }^{*} \mathrm{C}$ \\
\hline 9 & Temperatur udara Masuk & $T_{n}$ & 29 & 29 & ${ }^{*} \mathrm{C}$ \\
\hline 10 & Temperatur udara Keluar & $T_{\omega}$ & 65 & 65 & c \\
\hline 12 & Laju Aliran Mata gas & $m$ & 10.43 & 10.43 & kgs \\
\hline 13 & Laju Aliran Masus udara & $m$ & 13.46 & 13.46 & $\mathrm{~kg} / \mathrm{s}$ \\
\hline 14 & Pinch Ratio & $P R$ & 1.50 & 1.50 & \\
\hline 15 & Savunan antar tube & $C l$ & 45 & 45 & Derajat \\
\hline 16 & Jumlah one pass & $C T P$ & 0.93 & 0.93 & \\
\hline
\end{tabular}

Selanjutnya untuk membuktikan hasil kondisi optimum hasil perhitungan secara teoritis dengan menggunakan metode eksperimen full factorial pada alat penukar kalor tipe shell dan tube untuk kondensor pada mesin pendingin, berdasarkan pada data tabel.4 diatas, hasil analisis dengan menggunakan program HTRI dapat diuraikan seperti dibawah ini:

- Kinerja Alat Penukar Kalor

(1). Koefisien Perpindahan Panas Konveksi disisi Cangkang

$$
\mathrm{h}_{\mathrm{o}}=776,77 \mathrm{~W} / \mathrm{m}^{2} \cdot \mathrm{K}
$$

(2). Koefisien Perpindahan Panas Konveksi disisi Pipa

$$
\mathrm{h}_{\mathrm{i}}=377,30 \mathrm{~W} / \mathrm{m}^{2} . \mathrm{K}
$$

(3). Koefisien Perpindahan Panas Menyeluruh Aktual

$$
\mathrm{U}_{\mathrm{a}}=243,88 \mathrm{~W} / \mathrm{m}^{2} \cdot \mathrm{K}
$$

(4). Koefisien Perpindahan Panas Menyeluruh Yang dibutuhkan

$$
\mathrm{U}_{\mathrm{d}}=238,60 \mathrm{~W} / \mathrm{m}^{2} \cdot \mathrm{K}
$$

(5). Kapasitas Pindah Panas (Duty)

$$
\mathrm{Q}=0,5763 \mathrm{MW}=576.300 \mathrm{Watt}
$$

(6). Luas Perpindahan Panas, $A=10,217 \mathrm{~m}^{2}$

(7). Over Design, $\mathrm{OD}=2,21 \%$

Berdasarkan hasil perhitungan kondisi optimum dengan menggunakan perhitungan eksperimental full factorial dibandingkan dengan simulasi program HTRI memiliki hasil yang mendekati sama atau dengan kata lain secara teoritis. Perbedaan hal ini terjadi dikarenakan masalah inputan dan proses numerik di dalam program persamaan analitik sederhana maupun dengan menggunakan program HTRI.

\section{KESIMPULAN}

Berdasarkan analisa hasil pengolahan data dengan menggunakan metode eksperimen full factorial untuk menentukan desain dimensi utama alat yang optimum dari pengering tapioka diperoleh kesimpulan sebagai berikut:

- Desain alat penukar kalor setelah divalidasi menggunakan piranti lunak HTRI layak untuk diaplikasikan dalam operasional yang sesungguhnya dilapangan Dengan dimensi yang kecil, panjang $5 \mathrm{~m}$ dan diameter $377 \mathrm{~mm}$ dapat mempersempit lahan yang digunakan untuk mengeringkan tapioka.

- Alat penukar kalor yang menggunakan energi panas gas buang mesin diesel ini dapat dioperasikan pada kondisi cuaca apa saja baik saat musim penghujan maupun musim kemarau 
sehingga produksi tepung tapioka berjalan secara kontinyu.

Kondisi optimum desain dimensi alat penukar kalor dari pengering tapiokashell dan tube dengan metode eksperimen full factorial adalah sebagai berikut:

- Dari ke-81 hasil perhitungan desain dimensi pengering tapiokatersebut diatas terdapat desain dimensi pengering tapioka yang paling optimum, yaitu kondisi desain no 53 dengan jumlah tube 13,02 dan panjangtube $5 \mathrm{~m}$,serta koefisien perpindahan panas global U sebesar 240,51 $\mathrm{W} / \mathrm{m}^{2} . \mathrm{K}$ kondisi desain ini dipilih adalah adanya faktor jumlah tube yang sedikit, dan mempunyai nilai perpindahan panas global $U$ yang besar.

- Berdasarkan jumlah tube dan panjangtube dari kondisi desain tersebut maka kondisi desain yang paling optimum dengan jumlah tube 13,02 yaitu dengan diameter tube $0.0508 \mathrm{~m}$, panjangtube $5 \mathrm{~m}$, susunan antar tube $C L, 45^{\circ}$, jarak antar tube $P R 1.5$ dan Number of Transfer Unit NTU 0,24

\section{DAFTAR PUSTAKA}

[1] A. Bejan and A. D. Karrus, Heat Transfer Handbook, New York: John Wiley \& Son.Inc, 2003.

[2] Y. A. Cengel and M. A. Boles, Thermodynamic an Engineering Approach Sixth Edition, McGraww-Hill Higher Education, 2007.

[3] M. J. Moran and H. N. Shapiro, Fundamentals of Engineering Thermodynamics, 4.th Ed, New York: John Wiley \& Sons, Inc., 2000.

[4] B. R. Munson and et al, Fundamentals of Fluid Mechanics, 4th. Ed, New York: John Wiley \& Sons. Inc, 2002.

[5] R. K. Shah and D. P. Sekulic, Fundamental of Heat Exchanger Design, New York: John Wiley \& Son.Inc, 2003.

[6] M. R. Grace, "Cassava Processing," FAO Plant Production and Protection Series, Agriculture Buletin, Itali, 1977.
[7] J. Callister and D. William, Materials Science and Engineering an Introduction, 6th Ed, New York: John Wiley \& Sons, Inc., 2003. 